\title{
Effects of renal denervation on sympathetic activation, blood pressure, and glucose metabolism in patients with resistant hypertension
}

\author{
Markus P. Schlaich 1,2,3 *, Dagmara Hering ${ }^{1}$, Paul Sobotka ${ }^{4}$, Henry Krum ${ }^{5}$, Gavin W. Lambert ${ }^{1,3}$, \\ Elisabeth Lambert ${ }^{1,3}$ and Murray D. Esler ${ }^{1}$
}

\author{
${ }^{1}$ Neurovascular Hypertension and Kidney Disease and Human Neurotransmitters Laboratories, Baker IDI Heart and Diabetes Institute, Melbourne, VIC, Australia \\ 2 Heart Centre, Alfred Hospital, Melbourne, VIC, Australia \\ ${ }^{3}$ Department of Physiology, Nursing and Health Sciences, Monash University, Melbourne, VIC, Australia \\ ${ }^{4}$ Department of Medicine, Hennepin County Medical Center, University of Minnesota, Minneapolis, MN, USA \\ ${ }^{5}$ Department of Epidemiology and Preventive Medicine, Monash Centre of Cardiovascular Research and Education in Therapeutics, Monash University, Melbourne, \\ VIC, Australia
}

\section{Edited by:}

Jacqueline Kathleen Phillips,

Macquarie University, Australia

\section{Reviewed by:}

Gregory Fink, Michigan State

University, USA

Olaf Grisk, University of Greifswald,

Germany

\section{*Correspondence:}

Markus P. Schlaich, Neurovascular Hypertension and Kidney Disease

Laboratory, Baker IDI Heart and

Diabetes Institute, PO Box 6492, St

Kilda Road Central, Melbourne, VIC

8008, Australia.

e-mail:markus.schlaich@

bakeridi.edu.au
Increased central sympathetic drive is a hallmark of several important clinical conditions including essential hypertension, heart failure, chronic kidney disease, and insulin resistance. Afferent signaling from the kidneys has been identified as an important contributor to elevated central sympathetic drive and increased sympathetic outflow to the kidney and other organs is crucially involved in cardiovascular control. While the resultant effects on renal hemodynamic parameters, sodium and water retention, and renin release are particularly relevant for both acute and long term regulation of blood pressure, increased sympathetic outflow to other vascular beds may facilitate further adverse consequences of sustained sympathetic activation such as insulin resistance, which is commonly associated with hypertension. Recent clinical studies using catheter-based radiofrequency ablation technology to achieve functional renal denervation in patients with resistant hypertension have identified the renal nerves as therapeutic target and have helped to further expose the sympathetic link between hypertension and insulin resistance. Initial data from two clinical trials and several smaller mechanistic clinical studies indicate that this novel approach may indeed provide a safe and effective treatment alternative for resistant hypertension and some of its adverse consequences.

Keywords: renal denervation, hypertension, sympathetic

\section{INTRODUCTION}

Although a common and growing clinical problem, there is a lack of data on the exact prevalence of resistant hypertension, which is commonly defined as blood pressure (BP) above target levels despite the use of at least three antihypertensive agents in adequate doses from different classes, typically including a diuretic (Calhoun et al., 2008). Evidence from the National Health and Nutrition Examination Survey and from large randomized clinical trials indicate that up to $20-30 \%$ of hypertensive patients require three or more antihypertensive agents to achieve $\mathrm{BP}$ targets. Failure to reach target BP levels despite therapeutic intervention leaves patients at high risk for major cardiovascular events (Calhoun et al., 2008). Developing additional approaches to the current management of resistant hypertension consisting of lifestyle modification combined with poly-pharmacotherapy remains a priority.

\section{THE SYMPATHETIC NERVOUS SYSTEM AND BLOOD PRESSURE REGULATION}

While the pathogenesis of arterial hypertension is multi-factorial, there is unequivocal evidence for an important role of the sympathetic nervous system as a major contributor to the development of hypertension and its adverse consequences with the BP elevation being initiated and sustained by elevated sympathetic nerve activity (Esler, 2000). Increased sympathetic outflow to the heart resulting in increased cardiac output and neurally mediated vasoconstriction of peripheral blood vessel are obvious examples of neural pathways leading to elevated BP. The consequences of increased sympathetic outflow to the kidneys, perhaps most important in this context, are sodium and water retention, increased renin release and alterations of renal blood flow (DiBona and Kopp, 1997), effects that again contribute substantially to BP elevations, both acutely and in the long term (Esler, 2000; Schlaich et al., 2009a). Furthermore, sympathetic nervous system activation has also been implicated in alterations of glucose metabolism and is evident in obese patients, patients with the metabolic syndrome, and patients with diabetes (Lambert et al., 2010). Of note, hypertension and alterations of glucose metabolism regularly coincide with the sympathetic nervous system being an obvious but not the only link between the two (Lambert et al., 2010). Accordingly, targeting the sympathetic nervous system directly appears to be a logical therapeutic approach not only for the treatment of hypertension but perhaps also for additional adverse consequences associated with sympathetic activation. 


\section{THE SPECIFIC ROLE OF RENAL SYMPATHETIC NERVES FOR HYPERTENSION AND CV OUTCOMES}

The renal nerves are major regulators of kidney function, volume homeostasis, and BP control (DiBona and Kopp, 1997). Assessment of regional overflow of norepinephrine (NE) from the kidneys to plasma clearly demonstrated that renal norepinephrine spillover rates are markedly elevated in patients with essential hypertension (Schlaich et al., 2004) and are associated with hypertensive target organ damage such as left ventricular (LV) hypertrophy (Schlaich et al., 2003; Burns et al., 2007). Interestingly, activation of cardiorenal sympathetic nerve activity is even more pronounced in heart failure (Kaye et al., 1994), a common clinical consequence of long term and sustained elevated BP. Renal sympathetic activation has been shown to predict all-cause mortality and heart transplantation in patients with congestive heart failure (Kaye et al., 1995). Similarly, elevated norepinephrine plasma levels have been identified as major contributors to adverse CV outcomes in end-stage renal disease (Zoccali et al., 2002), another condition commonly characterized by substantially elevated sympathetic nerve activity (Schlaich et al., 2009a). There is now also substantial evidence for a specific role of sympathetic activation in the progression of chronic kidney disease (Grassi et al., 2011), which in turn is often a consequence of long term uncontrolled BP (Schlaich et al., 2009a).

Increased efferent nerve activity mediates changes in renal function through innervations of all essential renal structures including the renal vasculature, the tubules, and the juxtaglomerular apparatus (DiBona and Kopp, 1997). Consequently, renal sympathetic activation results in volume retention, sodium reabsorption, reduction of blood flow, and renin-angiotensin-aldosterone system activation (DiBona and Kopp, 1997). The kidney however, also has an extensive network of afferent unmyelinated fibers that transmit important sensory information to the central nervous system (CNS; Stella and Zanchetti, 1991; DiBona and Kopp, 1997). Afferent fibers from the kidney have been shown to travel along with the sympathetic nerves at the level of the kidney and then enter the dorsal roots and project to neurons at both spinal and supraspinal levels. Most of the brainstem regions involved in cardiovascular control including the hypothalamus receive inputs from the renal afferents which carry information to the CNS from renal chemo- and mechano-receptors (Stella and Zanchetti, 1991; DiBona and Kopp, 1997). Direct electrical stimulation of the renal afferent nerves in animals may produce both sympathoinhibitory and sympathoexcitatory reflexes, which reflects the diverse functional nature of various populations of renal receptors (Stella and Zanchetti, 1991). While much less is known about the normal function of the renal afferent nerves than the efferent nerves, there is evidence that renal afferents play a role in the reflex increase in sympathetic tone that occurs in hypertension (Katholi, 1983). Renal afferent nerve activity directly influences sympathetic outflow to the kidneys and other highly innervated organs involved in cardiovascular control such as the heart and peripheral blood vessels, predominantly by modulating posterior hypothalamic activity (DiBona and Kopp, 1997; Ye et al., 1997). Interestingly, abrogation of renal sensory afferent nerves has been demonstrated to reduce both BP and organ specific damage caused by chronic sympathetic overactivity in various experimental models (DiBona,
2003). Targeting the renal nerves specifically therefore appears as an obvious therapeutic strategy. Indeed, recent efforts to functionally denervate the human kidneys by targeting both efferent and afferent nerves directly via a novel catheter-based ablation approach has sparked substantial interest in this technique as a novel treatment strategy particularly for resistant hypertension, but perhaps also for less severe forms of hypertension and other conditions characterized by increased sympathetic drive (Schlaich et al., 2010).

\section{BENEFICIAL CONSEOUENCES OF THERAPEUTIC RENAL DENERVATION}

Renal denervation has been widely applied in experimental models of various conditions characterized by heightened sympathetic drive and consistently demonstrated the importance of renal efferent and afferent nerves and their contribution to the pathophysiology of hypertension, heart failure, and chronic kidney disease (Schlaich et al., 2009b). In a large number of diverse animal models of experimental hypertension including genetic, salt sensitive, and obesity hypertension, bilateral renal denervation prevented the development or attenuated the magnitude of hypertension (DiBona and Kopp, 1997).

Although more difficult to assess in humans, there is convincing evidence of increased sympathetic activity in various forms of hypertension including essential hypertension (Esler, 2000), obesity related hypertension (Esler et al., 2006), renal hypertension (Schlaich, 2011), hypertension associated with obstructive sleep apnea (Peppard et al., 2000), and preeclampsia (Schobel et al., 1996).

\section{CATHETER-BASED RENAL DENERVATION: CLINICAL TRIAL DATA AND MECHANISTIC INSIGHTS}

Against this background, a recent safety and proof-of concept study for the first time applied a novel catheter-based technique to selectively denervate the kidneys in patients with treatment resistant hypertension (Krum et al., 2009). In this approach, renal nerve ablation is achieved percutaneously via the lumen of the renal artery using a catheter connected to a radiofrequency (RF) generator. After the treatment catheter (Symplicity ${ }^{\circledR}$, Ardian, Inc., Palo Alto, CA, USA) is introduced, four to six discrete RF ablations are applied and separated both longitudinally and rotationally within each renal artery (Figure 1). Catheter tip temperature and impedance are constantly monitored during ablation and $\mathrm{RF}$ energy delivery is regulated according to a predetermined algorithm.

A total of 45 patients with a mean age of $58 \pm 9$ years and an average BP of $177 / 101 \pm 20 / 15 \mathrm{mmHg}$ despite concurrent use of a mean of $4.7 \pm 1.5$ antihypertensive agents were treated. Vascular safety analysis consisting of renal angiography at 14-30 days after the procedure and MR angiographies at 6 months postprocedure revealed no instances of renal artery aneurysm or stenosis or other major long term adverse events. Renal function remained unchanged, indicative of a favorable vascular and renal safety profile. The ablation procedure is typically accompanied by diffuse visceral non-radiating abdominal pain which does not persist beyond the RF energy application and can be managed by intravenous narcotics and sedatives. 

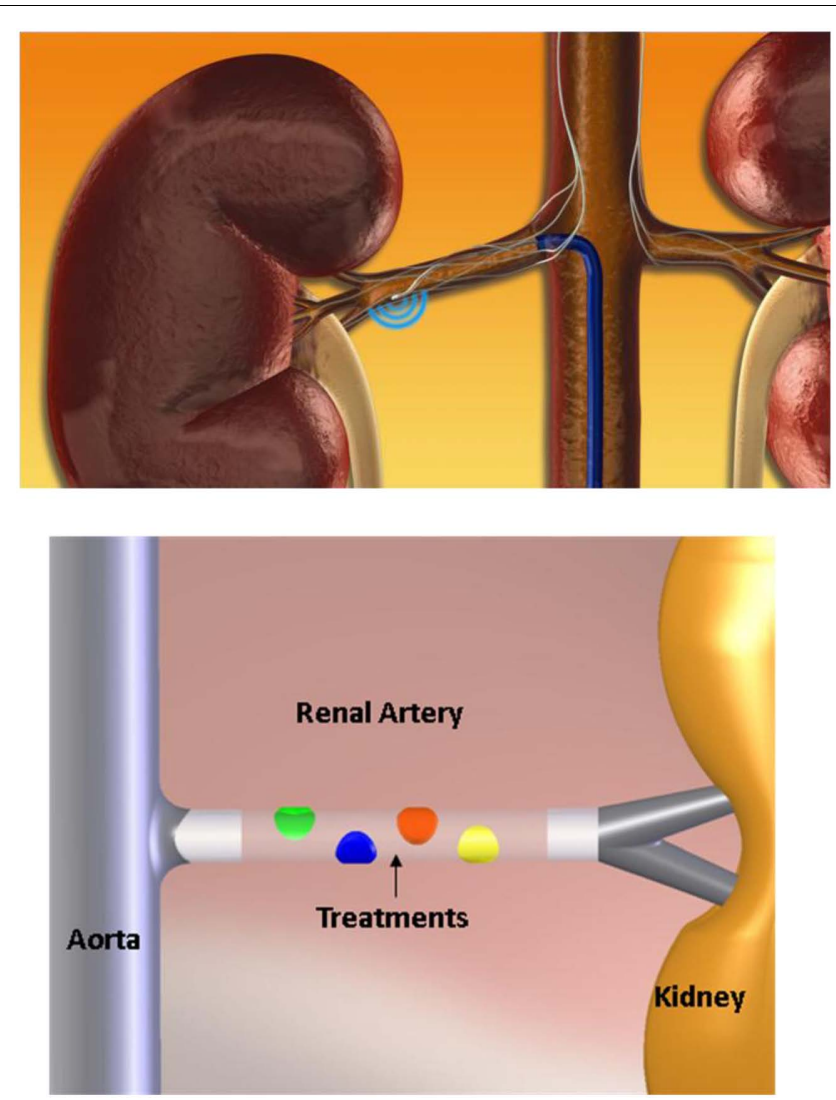

FIGURE 1 | Schematic illustration of the percutaneous catheter-based approach to functionally denervate the human kidney. Similar to a routine angiogram access to the renal artery is obtained via a sheath in the femoral artery. The treatment catheter is then introduced into the renal artery and discrete RF ablation treatments lasting 2 min each are applied along the renal artery as illustrated. Up to six ablations are performed in each artery which are separated both longitudinally and rotationally to achieve circumferential coverage of the renal artery. Catheter tip temperature and impedance are constantly monitored during ablation and RF energy delivery is regulated according to a predetermined algorithm.

From a clinical perspective, the most important result of this trial was that renal nerve ablation is associated with a significant and sustained reduction in both systolic and diastolic office BP up to 12 months follow up with mean $( \pm 95 \% \mathrm{CI})$ decreases of $-14 /-10 \pm 4 / 3,-21 /-10 \pm 7 / 4,-22 /-11 \pm 10 / 5$, $-24 /-11 \pm 9 / 5$, and $-27 /-17 \pm 16 / 11 \mathrm{mmHg}$ at $1,3,6,9$, and 12 months, respectively.

From a mechanistic point of view, it seemed important to document the effectiveness of the procedure to reduce renal sympathetic nerve activity. Radiotracer dilution methodologies were therefore applied to assess overflow of norepinephrine from the kidneys into the circulation before and after the procedure. These analyses revealed a substantial reduction in mean norepinephrine spillover by $47 \%$ (95\% confidence interval: $28-65 \%$ ) 1 month after bilateral denervation. Furthermore, it is also noteworthy that renal denervation decreased renin secretion and increased renal blood flow (Schlaich et al., 2009c), confirming successful targeting of efferent renal nerves.
While the contribution of afferent nerves cannot be measured directly in humans, the demonstration of a substantial and progressive reduction in central sympathetic outflow from baseline through to 12 months follow up is perhaps indicative of similar alterations in afferent fiber signaling that may well play an important role in the BP effects associated with this procedure (Schlaich et al., 2009c). Further support for a role o afferent nerves in this scenario may be derived from experimental studies demonstrating that rats subjected to renal surgical denervation experience functional reinnervation of the renal vasculature which begins to occur between 14 and 24 days after denervation, with complete return of neural function by 8 weeks (Kline and Mercer, 1980). It is therefore possible that some efferent sympathetic reinnervation may occur in patients after renal denervation, although the magnitude and time course of this potential response is unknown. Interestingly, in contrast to efferent nerves, the afferent nerves do not appear to have the capacity to regrow (Arrowood et al., 1995), thereby perhaps explaining the sustained BP lowering effect of renal denervation over time via the removal of renal afferent activity and the subsequent effects on central sympathetic outflow (Schlaich et al., 2009c). Indeed, a very recent analysis summarizing the experience from longer term follow up of the initial cohort $(n=45)$ and similar patients subsequently treated with catheter-based renal denervation in a non-randomized and uncontrolled fashion (total $n=153$ ) demonstrated the sustained efficacy of renal nerve ablation with post-procedure office BP being reduced by $32 / 14 \mathrm{mmHg}$ at 24 months follow up (Krum et al., 2011; Figure 2).

Additional factors that may translate into better outcomes after renal denervation include improvements in cardiac baroreflex sensitivity (from 7.8 to $11.7 \mathrm{~ms} / \mathrm{mmHg}$ ) and a reduction in $\mathrm{LV}$ mass from 184 to $169 \mathrm{~g}\left(78.8-73.1 \mathrm{~g} / \mathrm{m}^{2}\right)$ at 12 months follow up compared to baseline (Schlaich et al., 2009c).

Very recently, results from the first randomized controlled clinical trial including a total of 106 patients were published (Esler et al., 2010). Inclusion criteria were similar to those of the initial safety and proof-of concept trial with patients required to have a baseline systolic office $\mathrm{BP} \geq 160 \mathrm{mmHg}(\geq 150 \mathrm{mmHg}$ for patients with type 2 diabetes) despite compliance with $\geq 3$ antihypertensive medications. Patients were then randomized to either undergo renal nerve ablation treatment $(n=52)$ or to continue with conventional drug treatment as part of the control group $(n=54)$.

Both groups had similar baseline characteristics and antihypertensive regimen with the exception of estimated glomerular filtration rate (eGFR) which was lower in the active treatment group (77 vs. $86 \mathrm{ml} / \mathrm{min}, p=0.013$ ). Peri-procedural events requiring treatment were rare. In keeping with the results from the first trial, a significant difference in the primary endpoint of seated office BP of $33 / 11 \mathrm{mmHg}(p<0.001$ for both systolic and diastolic BP) was noted between the renal denervation group and the control group. Home BP recordings confirmed the observed office BP changes with a reduction in home BP by $20 / 12 \pm 17 / 11 \mathrm{mmHg}$ in the renal denervation group and a rise of $2 / 0 \pm 13 / 7 \mathrm{mmHg}$ in the control group ( $p<0.001$; Figure 3 ). BP control defined as systolic $\mathrm{BP}<140 \mathrm{mmHg}$ was achieved in $39 \%$ of patients in the denervation group and in $3 \%$ of patients in the control group. However, it is also important to note that there is substantial variability in regards 


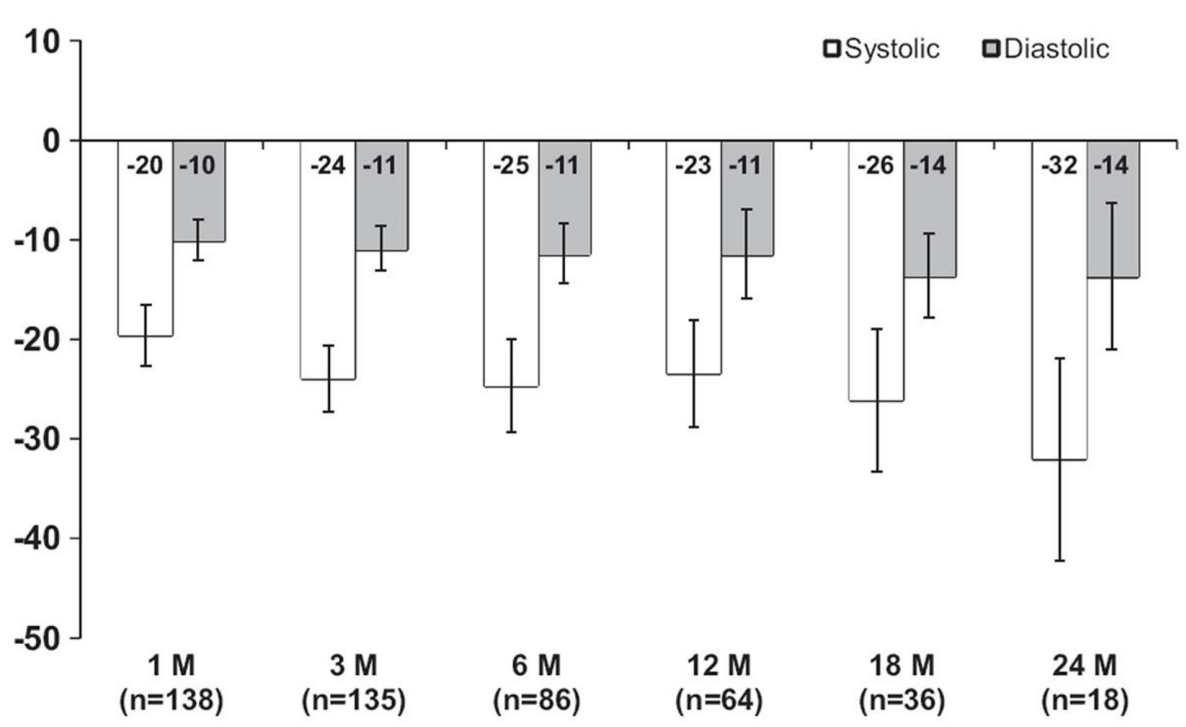

FIGURE 2 | Mean systolic and diastolic blood pressure changes from baseline after renal denervation with up to 2 years of follow up.

to the $\mathrm{BP}$ effects and that the procedure fails to reduce $\mathrm{BP}$ in $\sim 10 \%$ of treated patients. Whether this may be related to age of patients, duration of hypertension, established target organ damage, the number of ablation treatments or other factors is currently unclear.

\section{RENAL DENERVATION AND GLUCOSE METABOLISM}

While the available evidence indicates that catheter-based renal denervation has a favorable safety profile and results in substantial and sustained BP reduction in patients with drug resistant hypertension, the benefit of renal denervation may not be restricted to BP lowering alone. Hypertension is frequently associated with metabolic alterations such as overweight and obesity, impaired fasting glucose, impaired glucose tolerance, and insulin resistance and sympathetic activation has clearly been identified as an important contributor to this detrimental clinical scenario (Lambert et al., 2010). Sympathoinhibition would therefore be expected to improve glycemic control (Straznicky et al., 2011a). Indeed, in a group of patients who either had renal denervation $(n=37)$ or served as controls $(n=13)$, detailed assessment of glucose metabolism was performed by assessing fasting glucose, insulin, C-peptide, HbAlc, calculated insulin sensitivity (HOMAIR), and glucose levels during oral glucose tolerance test (OGTT) at baseline and at 1 and 3 months follow up (Mahfoud et al., 2011). In addition to the BP fall observed in the treatment group $(-32 /-12 \mathrm{mmHg})$ after 3 months, fasting glucose [from $118 \pm 3.4$ to $108 \pm 3.8 \mathrm{mg} / \mathrm{dl}(p=0.039)$ ], insulin levels [from $20.8 \pm 3.0$ to $9.3 \pm 2.5 \mu \mathrm{IU} / \mathrm{ml}(p=0.006)$ ], C-peptide levels [from $5.3 \pm 0.6$ to $3.0 \pm 0.9 \mathrm{ng} / \mathrm{ml}(p=0.002)$ ], and the HOMA-IR [ from $6.0 \pm 0.9$ to $2.4 \pm 0.8(p=0.001)]$ also improved significantly after 3 months (Figure 4). Additionally, mean 2-h glucose levels during OGTT were reduced significantly by $27 \mathrm{mg} / \mathrm{dl}(p=0.012)$ while there were no significant changes in BP or any of the metabolic markers in the control group.

Further support for such a beneficial role comes from investigations of yet another group of patients commonly characterized by overweight or obesity, sympathetic nervous system activation, insulin resistance, and BP elevation, namely women with polycystic ovary syndrome. Using the gold standard methodology of euglycemic hyperinsulinemic clamp, it was demonstrated that insulin sensitivity improved by $17.5 \%$ in the absence of any weight changes at 3 months after renal denervation. Of note, glomerular hyperfiltration and urinary albumin excretion were also reduced indicating that the benefits of renal denervation may also extend to renal structure and function, as suggested previously (Schlaich et al., 2009a,b; Straznicky et al., 2011b).

While the effects of renal denervation on glucose metabolism described above are primarily of descriptive nature, there is ample evidence highlighting potential mechanisms through which inhibition of sympathetic activation could improve glucose metabolism.

In the human forearm, increased noradrenaline release results in a substantial reduction in forearm blood flow (Jamerson et al., 1993). This is associated with a markedly reduced uptake of glucose, demonstrating the adverse effect of sympathetic activation on the ability of the cell to transport glucose across its membrane (Jamerson et al., 1993). Experimental and clinical data indicate that the rate of diffusion of a substance decreases with the square of the distance to its target (Rasio, 1975), that there is a direct relationship between the sympathetic nerve firing rate to skeletal muscle tissue and insulin resistance (Grassi et al., 2004) and that insulin resistance is inversely related to the number of open capillaries (Egan, 1991). Furthermore, this situation may be enhanced if insulin resistance is already established, a state in which the ability of insulin to increase muscle perfusion has been demonstrated to be reduced by $\sim 30 \%$ (Laakso et al., 1990). In view of these data it is perhaps not surprising that a procedure that reduces sympathetic nerve activity can also result in improvements of glucose metabolism. 


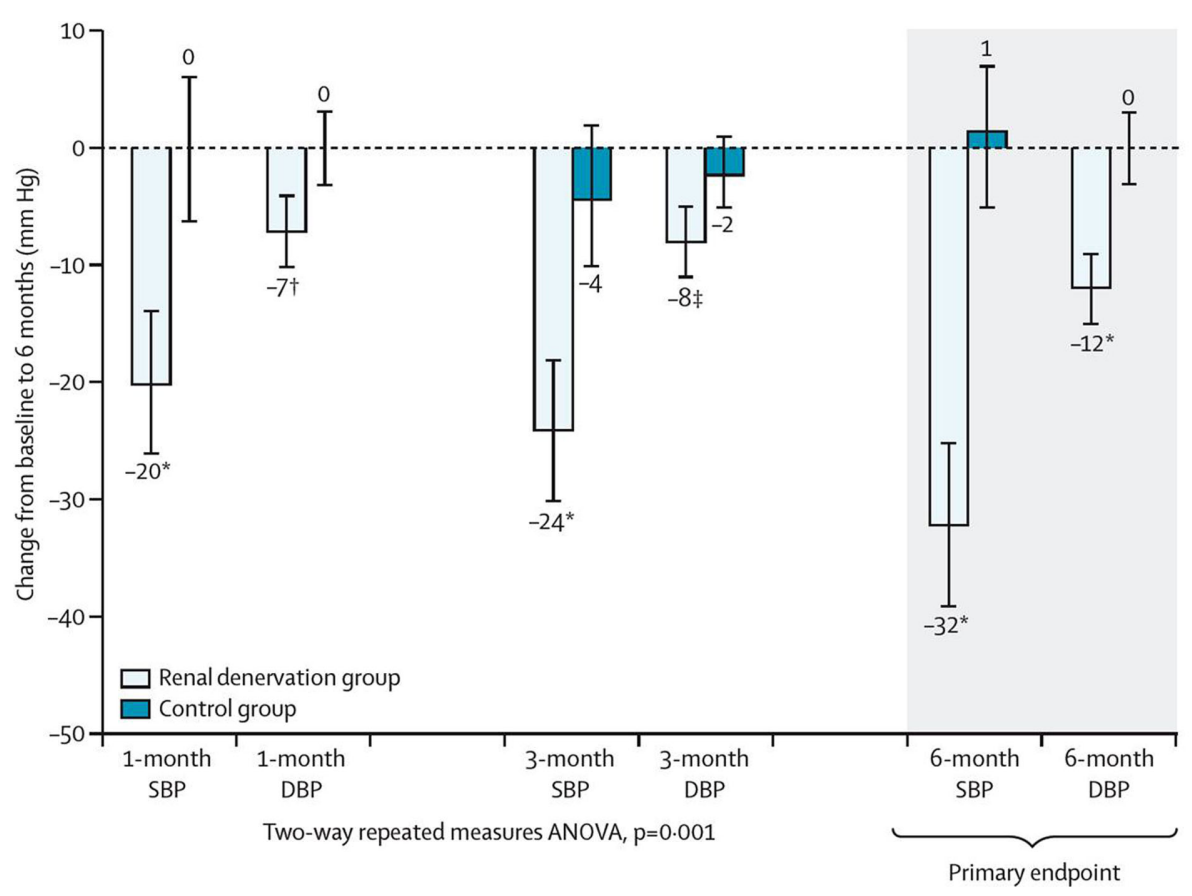

FIGURE 3 | Change in systolic and diastolic office blood pressure in the renal denervation group and the control group, respectively.
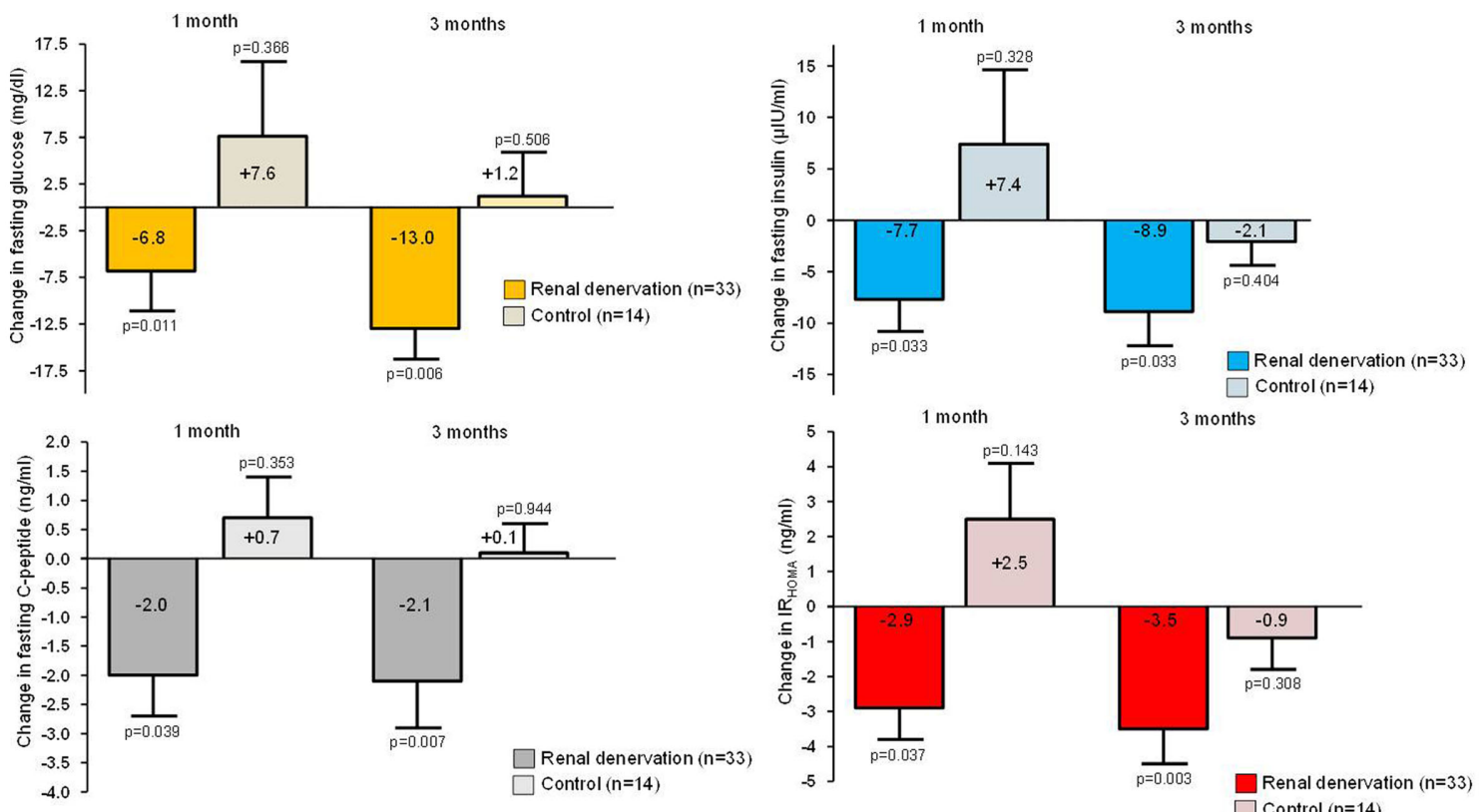

Control $(n=14)$

FIGURE 4 | Change in fasting glucose, insulin levels, C-peptide levels, and the HOMA-IR in the renal denervation group and the control group, respectively.

\section{CONCLUSION}

In summary, findings from the initial safety and proof-of-concept study and one randomized controlled clinical trial indicate that renal nerve ablation achieved via a novel catheter-based approach using RF energy is safe and has the potential to improve BP control and alleviate the sequelae of elevated BP in patients with resistant hypertension. These beneficial effects appear to be mediated via interference with both efferent and afferent 
nerves and are likely to extend to improvements in metabolic control.

Whether this novel approach may also be useful in less severe forms of hypertension or in other conditions characterized by heightened renal sympathetic nerve activity such as chronic and end-stage renal disease needs to be determined in future studies. On the basis of the known pathophysiology, patients with either chronic or end-stage renal disease and those with heart failure also appear to be suitable candidates for such an approach, given the

\section{REFERENCES}

Arrowood, J. A., Goudreau, E., Minisi, A. J., Davis, A. B., and Mohanty, P. K. (1995). Evidence against reinnervation of cardiac vagal afferents after human orthotopic cardiac transplantation. Circulation 92, 402-408.

Burns, J., Sivananthan, M. U., Ball, S. G., Mackintosh, A. F., Mary, D. A., and Greenwood, J. P. (2007). Relationship between central sympathetic drive and magnetic resonance imaging-determined left ventricular mass in essential hypertension. Circulation 115, 1999-2005.

Calhoun, D. A., Jones, D., Textor, S., Goff, D. C., Murphy, T. P., Toto, R. D., White, A., Cushman, W. C., White, W., Sica, D., Ferdinand, K., Giles, T. D., Falkner, B., Carey, R. M., and American Heart Association Professional Education Committee. (2008). Resistant hypertension: diagnosis, evaluation, and treatment. A scientific statement from the American Heart Association Professional Education Committee of the Council for high blood pressure research. Hypertension 51, 1403-1419.

DiBona, G. F. (2003). Neural control of the kidney: past, present, and future. Hypertension 41, 621-624.

DiBona, G. F., and Kopp, U. C. (1997). Neural control of renal function. Physiol. Rev. 77, 75-197.

Egan, B. M. (1991). Neurohumoral, hemodynamic and microvascular changes as mechanisms of insulin resistance in hypertension: a provocative but partial picture. Int. J. Obes. 15(Suppl. 2), 133-139.

Esler, M. (2000). The sympathetic system and hypertension. Am. J. Hypertens. 13, 99S-105S.

Esler, M., Straznicky, N., Eikelis, N., Masuo, K., Lambert, G., and Lambert, E. (2006). Mechanisms of sympathetic activation in obesityrelated hypertension. Hypertension 48, 787-796.

Esler, M. D., Krum, H., Sobotka, P. A., Schlaich, M. P., Schmieder, R. E., and Bohm, M. (2010). Renal sympathetic denervation in patients with treatment-resistant hypertension (The Symplicity HTN2 Trial): a randomised controlled trial. Lancet 376, 1903-1909.

Grassi, G., Dell'Oro, R., Facchini, A., Quarti Trevano, F., Bolla, G. B., and Mancia, G. (2004). Effect of central and peripheral body fat distribution on sympathetic and baroreflex function in obese normotensives. $J$. Hypertens. 22, 2363-2369.

Grassi, G., Quarti-Trevano, F., Seravalle, G., Arenare, F., Volpe, M., Furiani, S., Dell'Oro, R., and Mancia, G. (2011). Early sympathetic activation in the initial clinical stages of chronic renal failure. Hypertension 57, 846-851.

Jamerson, K. A., Julius, S., Gudbrandsson, T., Andersson, O., and Brant, D. O. (1993). Reflex sympathetic activation induces acute insulin resistance in the human forearm. Hypertension 21, 618-623.

Katholi, R. E. (1983). Renal nerves in the pathogenesis of hypertension in experimental animals and humans. Am. J. Physiol. 245, F1-F14.

Kaye, D. M., Lambert, G. W., Lefkovits, J., Morris, M., Jennings, G., and Esler, M. D. (1994). Neurochemical evidence of cardiac sympathetic activation and increased central nervous system norepinephrine turnover in severe congestive heart failure. J. Am. Coll. Cardiol. 23, 570-578.

Kaye, D. M., Lefkovits, J., Jennings, G. L. Bergin, P., Broughton, A., and Esler, M. D. (1995). Adverse consequences of high sympathetic nervous activity in the failing human heart. J. Am. Coll. Cardiol. 26, 1257-1263.

Kline, R. L., and Mercer, P. F. (1980). Functional reinnervation and development of supersensitivity to NE after renal denervation in rats. Am. J. Physiol. 238, R353-R358.

Krum, H., Barman, N., Schlaich, M., Sobotka, P., Esler, M., Mahfoud, F., Bohm, M., Dunlap, M., Sadowski, J., Bartus, K., Kapelak, B., Rocha-Singh, K. J., Katholi, R. E., Witkowski, A., Kadziela, J., Januszewicz, A., Prejbisz, A., Walton, A. S., Sievert, H., Id, D., Wunderlich, N., Whitbourn, R., Rump, L. C., Vonend, O., Saleh, A., Thambar, S., Nanra, R., Zeller, T., Erglis, A., Sagic, D., Boskovic, S.,

evidence from both experimental and human studies to indicate that efferent and afferent signaling are crucially involved in the sympathetic activation almost invariably present in these patients. Other patients who may benefit from such an approach are those intolerant to pharmacological treatment. Several clinical trials are currently being conducted and planned to further substantiate the BP lowering efficacy of this novel renal denervation procedure and to identify patient cohorts that are likely to benefit from such an approach.

Brachmann, J., Schmidt, M., Wenzel, U. O., Bart, B. A., Schmieder, R. E., Scheinert, D., Börgel, J., and Straley, C. (2011). Catheter-based renal sympathetic denervation for resistant hypertension: durability of blood pressure reduction out to 24 months. Hypertension 57, 911-917.

Krum, H., Schlaich, M., Whitbourn, R., Sobotka, P. A., Sadowski, J., Bartus, K., Kapelak, B., Walton, A., Sievert, H., Thambar, S., Abraham, W. T., and Esler, M. (2009). Catheter-based renal sympathetic denervation for resistant hypertension: a multicentre safety and proof-of-principle cohort study. Lancet 373, 1275-1281.

Laakso, M., Edelman, S. V., Brechtel, G. and Baron, A. D. (1990). Decreased effect of insulin to stimulate skeletal muscle blood flow in obese man. A novel mechanism for insulin resistance. J. Clin. Invest. 85, 1844-1852.

Lambert, G. W., Straznicky, N. E. Lambert, E. A., Dixon, J. B., and Schlaich, M. P. (2010). Sympathetic nervous activation in obesity and the metabolic syndrome causes, consequences and therapeutic implications. Pharmacol. Ther. 126, 159-172.

Mahfoud, F., Schlaich, M., Kindermann, I., Ukena, C., Cremers, B., Brandt, M. C., Hoppe, U. C., Vonend, O., Rump, L. C., Sobotka, P. A., Krum, H. Esler, M., Boehm, M. (2011). Effect of renal sympathetic denervation on glucose metabolism in patients with resistant hypertension: a pilot study. Circulation 123, 1940-1946.

Peppard, P. E., Young, T., Palta, M., and Skatrud, J. (2000). Prospective study of the association between sleepdisordered breathing and hypertension. N. Engl. J. Med. 342, 1378-1384.

Rasio, E. A. (1975). Passage of glucose through the cell membrane of capillary endothelium. Am. J. Physiol. 228, 1103-1107.

Schlaich, M. P. (2011). Sympathetic activation in chronic kidney disease: out of the shadow. Hypertension 57, 683-685.

Schlaich, M. P., Kaye, D. M., Lambert, E., Sommerville, M., Socratous, F., and Esler, M. D. (2003). Relation between cardiac sympathetic activity and hypertensive left ventricular hypertrophy. Circulation 108, 560-565.

Schlaich, M. P., Krum, H., and Sobotka, P. A. (2010). Renal sympathetic nerve ablation: the new frontier in the treatment of hypertension. Curr. Hypertens. Rep. 12, 39-46.

Schlaich, M. P., Lambert, E., Kaye, D. M., Krozowski, Z., Campbell, D. J., Lambert, G., Hastings, J., Aggarwal, A., and Esler, M. D. (2004). Sympathetic augmentation in hypertension: role of nerve firing, norepinephrine reuptake, and angiotensin neuromodulation. Hypertension 43, 169-175.

Schlaich, M. P., Socratous, F., Hennebry, S., Eikelis, N., Lambert, E. A., Straznicky, N., Esler, M. D., and Lambert, G. W. (2009a). Sympathetic activation in chronic renal failure. $J$. Am. Soc. Nephrol. 20, 933-939.

Schlaich, M. P., Sobotka, P. A., Krum, H., Whitbourn, R., Walton, A., and Esler, M. D. (2009b). Renal denervation as a therapeutic approach for hypertension: novel implications for an old concept. Hypertension 54, 1195-1201.

Schlaich, M. P., Sobotka, P. A., Krum, H., Lambert, E., and Esler, M. D. (2009c). Renal sympathetic-nerve ablation for uncontrolled hypertension. N. Engl. J. Med. 361, 932-934.

Schobel, H. P., Fischer, T., Heuszer, K., Geiger, H., and Schmieder, R. E. (1996). Preeclampsia - a state of sympathetic overactivity. N. Engl. J. Med. 335, 1480-1485. [See comments].

Stella, A., and Zanchetti, A. (1991). Functional role of renal afferents. Physiol. Rev. 71, 659-682.

Straznicky, N. E., Grima, M. T., Eikelis, N., Nestel, P. J., Dawood, T., Schlaich, M. P., Chopra, R., Masuo, K., Esler, M. D., Sari, C. I., Lambert, G. W., and Lambert, E. A. (2011a). The effects of weight loss versus weight loss maintenance on sympathetic nervous system activity and metabolic syndrome components. J. Clin. Endocrinol. Metab. 96, E503-E508. 
Straznicky, N. E., Grima, M. T., Lambert, E. A., Eikelis, N., Dawood, T., Lambert, G. W., Nestel, P. J., Masuo, K., Sari, C. I., Chopra, R., Mariani, J. A., and Schlaich, M. P. (2011b). Exercise augments weight loss induced improvement in renal function in obese metabolic syndrome individuals. J. Hypertens. 29 , 553-564.

Ye, S., Ozgur, B., and Campese, V. M. (1997). Renal afferent impulses, the posterior hypothalamus, and hypertension in rats with chronic renal failure. Kidney Int. 51, 722-727.
Zoccali, C., Mallamaci, F., Parlongo, S., Cutrupi, S., Benedetto, F. A., Tripepi, G., Bonanno, G., Rapisarda, F., Fatuzzo, P., Seminara, G., Cataliotti, A., Stancanelli, B., and Malatino, L. S. (2002). Plasma norepinephrine predicts survival and incident cardiovascular events in patients with endstage renal disease. Circulation 105, 1354-1359.

Conflict of Interest Statement: MPS, $\mathrm{HK}$ and MD have been investigators in clinical trials sponsored by
Ardian Inc/Medtronic, the company that produces the renal denervation system and have received support for conference travel and lecture fees. PS is an employee of Ardian/Medtronic.

Received: 04 November 2011; accepted: 14 January 2012; published online: 02 February 2012.

Citation: Schlaich MP, Hering D, Sobotka P, Krum H, Lambert GW, Lambert E and Esler MD (2012) Effects of renal denervation on sympathetic activation, blood pressure, and glucose metabolism in patients with resistant hypertension. Front. Physio. 3:10. doi: 10.3389/fphys.2012.00010

This article was submitted to Frontiers in Integrative Physiology, a specialty of Frontiers in Physiology.

Copyright (C) 2012 Schlaich, Hering, Sobotka, Krum, Lambert, Lambert and Esler. This is an open-access article distributed under the terms of the Creative Commons Attribution Non Commercial License, which permits noncommercial use, distribution, and reproduction in other forums, provided the original authors and source are credited. 